\title{
Study on the Factors Affecting Ultrasonic Extraction of Flavonoids from Grapefruit Seed
}

\author{
Xian Qiu, Jing Wang, Minyi Lu and Yongguang $\mathrm{Bi}^{\mathrm{a}, \star}$
}

College of Pharmacy, Guangdong Pharmaceutical University, Guangzhou 510006, Guangdong,

China

abiyongguang2002@163.com

${ }^{*}$ Corresponding author:

Keywords: Grapefruit Seed; Flavonoids; Ultrasound; Single Factor; Test

\begin{abstract}
Ultrasonic extraction was studied by using single factor test using ethanol as extract material and ethanol extraction method. The results showed that the factors affecting the extraction of flavonoids from grapefruit were in the order of ratio of material to liquid, ultrasonic power, extraction time and extraction temperature. The extraction rate of flavonoids from grapefruit seed increased with the increase of the ratio of liquid to material. The extraction rate of flavonoids from grapefruit seed increased first and then decreased with the increase of ultrasonic power. With the increase of extraction temperature, The extraction rate of flavonoids from grapefruit was increased from $2.463 \mathrm{mg} / \mathrm{g}$ to $2.527 \mathrm{mg} / \mathrm{g}$. The extraction rate of flavonoids from grapefruit was increased from $25{ }^{\circ} \mathrm{C}$ to $65{ }^{\circ} \mathrm{C}$. The extraction rate of flavonoids from grapefruit seed increased with the increase of extraction time. When the extraction time increased from $20 \mathrm{~min}$ to $25 \mathrm{~min}$, the extraction rate increased from $2.343 \mathrm{mg} / \mathrm{mL}$ to $2.410 \mathrm{mg} / \mathrm{mL}$. When the extraction time was $30 \mathrm{~min}$, The extraction rate was reduced to $2.266 \mathrm{mg} / \mathrm{mL}$.
\end{abstract}

\section{Introduction}

Grapefruit, also known as grapefruit, text Dan, fragrant Luan, Zhu Luan, purple, etc., for Rutaceae Citrus trees. Grapefruit, a variety of grapefruit, orange, grapefruit, grapefruit grapefruit, grapefruit pear, grapefruit, orange grapefruit, citrus pomelo, citrus pomelo, etc., of which Shatian pomelo, grapefruit, pear grapefruit, Known as the world's four famous pomelo. Grapefruit originating in China, India, Malaysia area, in China's coastal Guangxi, Guangdong, Fujian, Zhejiang and other places are cultivated. Grapefruit seed for the grapefruit ripe fruit of the nuclear seed, usually in the month of the ripe fruit peeled peel peeled out of the seed ${ }^{[1]}$. At present, the research on grapefruit at home and abroad mainly focuses on grapefruit pulp and grapefruit skin. There are few studies on the active ingredients of grapefruit seed, and a lot of grapefruit seed is discarded in industrial production, resulting in waste of resources ${ }^{[2,3]}$. Studies have shown that grapefruit seeds are rich in flavonoids, flavonoids isolated from grapefruit seeds have higher medicinal value, such as oxygen free radicals, anti-inflammatory, anti-bacterial, anti-virus, so if the The extraction of grapefruit seed flavonoids in the production, not only to achieve the comprehensive utilization of grapefruit, to avoid waste of resources, but also for the treatment of the disease provides a new direction.

In recent years, ultrasonic technology began to extract the chemical composition of traditional Chinese medicine, showing a good application prospects. Experiments show that ultrasonic extraction can greatly improve the extraction rate of active ingredients, greatly shorten the extraction time, improve work efficiency, save solvent. In this study, ultrasonic extraction and alcohol extraction techniques were used to study the extraction process of flavonoids from grapefruit seed to determine the optimum conditions for extracting flavonoids from grapefruit seed by ultrasonic ${ }^{[4,5]}$. 


\section{Materials, Reagents and Instruments}

Grapefruit seed, from the local supermarkets in the Shatian pomelo obtained, dried after the shell, and dried at $60{ }^{\circ} \mathrm{C}$ constant temperature, crushed, over 40 mesh sieve, spare; Rutin, China Pharmaceutical Group Shanghai biochemical reagents plant; petroleum ether, UV-9100 UV-Vis spectrophotometer, Beijing Ruili Analytical Instruments; BL-320H-type electronic balance, Japan Shimadzu company; electric blast temperature Drying oven, Shanghai South electric furnace oven factory; digital constant temperature water bath, Guohua Electric Co., Ltd.

\section{Test Method}

Standard Curve Drawing. Accurately weighed $0.0150 \mathrm{~g}$ rutin standard, add the appropriate amount of $70 \%$ ethanol dissolved, constant volume to $100 \mathrm{~mL}$ rutin standard solution. Respectively, the standard solution of the above standard $2.00,4.00,6.00,8.00,10.00 \mathrm{~mL}$ in $25 \mathrm{~mL}$ volumetric flask, add $1 \mathrm{~mL}$ of 5\% NaNO2 solution, shake for $10 \mathrm{~min}$, then add $1 \mathrm{~mL} \mathrm{10 \%} \mathrm{A1} \mathrm{(NO3)} 3$ solution, shake Equilibrated for $10 \mathrm{~min}$, and finally $10 \mathrm{~mL}$ of $4 \% \mathrm{NaOH}$ solution was added and fixed to $25 \mathrm{~mL}$ with $70 \%$ ethanol and allowed to stand for $15 \mathrm{~min}$. The absorbance was measured at a wavelength of $510 \mathrm{~nm}$. Take the absorbance value $\mathrm{A}$ as the ordinate $(\mathrm{Y})$ and the rutin standard curve with the mass concentration $(\mathrm{mg} / \mathrm{mL})$ of rutin as the abscissa $(\mathrm{X})$.

Single Factor Test of Flavonoids Extracted from Grapef ruit Seed. The grapefruit seeds were treated with water bath degreasing in a water bath at $60{ }^{\circ} \mathrm{C}$ with petroleum ether as the degreasing solvent. The extraction rate of flavonoids from grapefruit seed was studied by using $70 \mathrm{~g}$ of ethanol as the extract, the ratio of material to liquid, the ultrasonic power, the extraction time and the extraction temperature. influences.

Determination of Flavonoids in Samples. Accurately measure $10.0 \mathrm{~mL}$ of grapefruit seed extract in a $25 \mathrm{~mL}$ volumetric flask, starting from "adding $1 \mathrm{~mL}$ of $5 \%$ NaNO2 solution" to "measuring absorbance at $510 \mathrm{~nm}$." In accordance with 2.1, the measured absorbance value is substituted into the regression equation $(\mathrm{Mg} / \mathrm{mL})$ of the flavonoids in the extract, and then the extraction rate of the flavonoids of the grapefruit seed was calculated according to the following formula:

Extraction rate $(\mathrm{mg} / \mathrm{g})=(\mathrm{C} \times \mathrm{V}) / \mathrm{W}$

Where $\mathrm{C}$ is the concentration of flavonoids in the test solution, $\mathrm{mg} / \mathrm{mL}$; $\mathrm{V}$ is the total volume of the extract, $\mathrm{mL} ; \mathrm{W}$ is the mass of the sample weighed, $\mathrm{g}$.

Orthogonal Test of Extraction of Flavonoids from Grapefruit Seed. According to the single factor test results, the L9 (34) orthogonal table was used for orthogonal test to determine the optimal extraction conditions.

\section{Results and Discussion}

Standard Curve Drawing. With the absorbance value A as the ordinate (Y), the concentration of rutin $(\mathrm{mg} / \mathrm{mL})$ as the abscissa $(\mathrm{X})$ to the rutin standard curve, as shown in Figure 1, the linear regression equation for the $\mathrm{Y}=11.847 \mathrm{X}+0.0008$. 


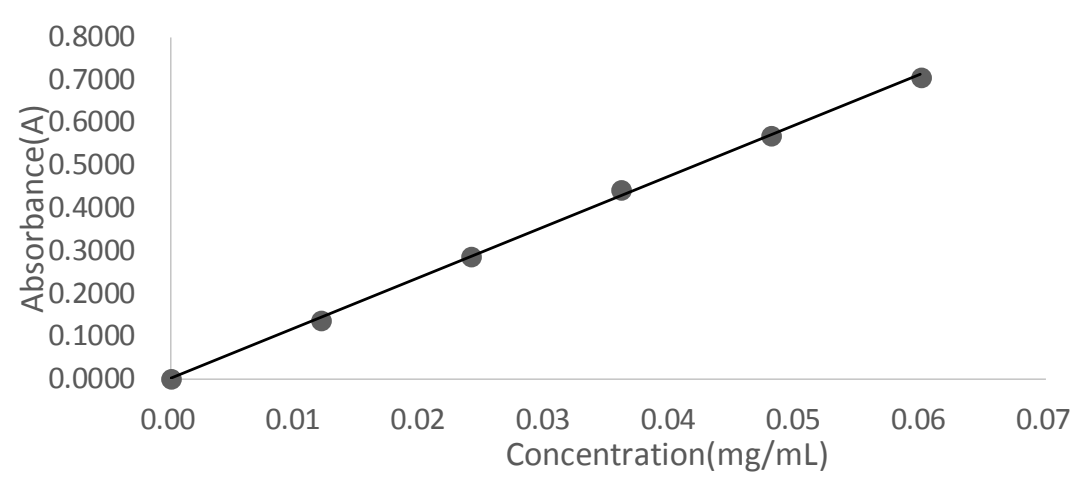

Figure 1. Standard curve

\section{Single Factor Test of Flavonoids Extracted from Grapefruit Seed}

1. Effect of Liquid Ratio on Extraction of Flavonoids from Grapefruit Seed

The extraction temperature was $50{ }^{\circ} \mathrm{C}$, the ultrasonic power was $240 \mathrm{w}$, the extraction time was $20 \mathrm{~min}$, and the ratio of material to liquid $(\mathrm{g} / \mathrm{mL})$ on the extraction of flavonoids from grapefruit was studied. The results are shown in Fig.2.

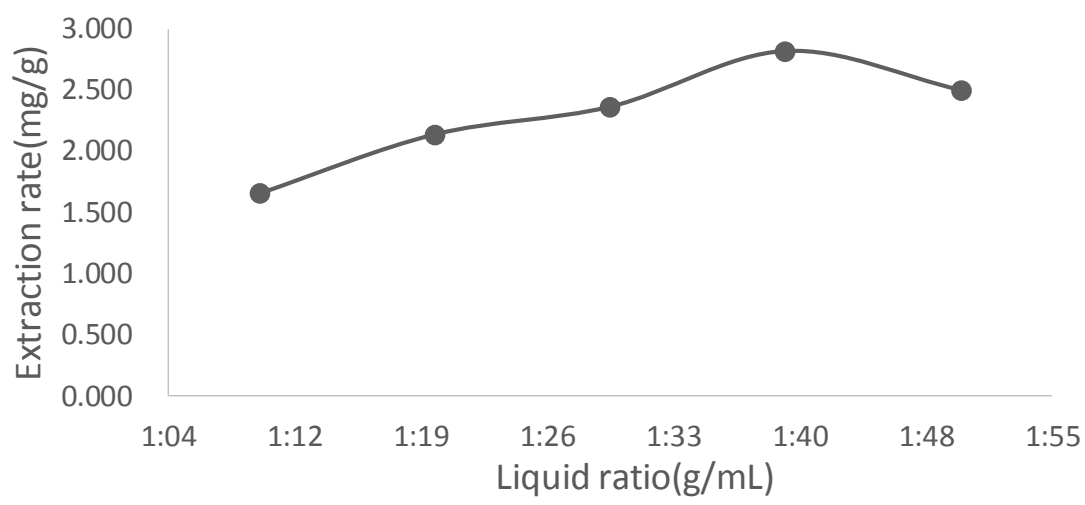

Figure 2. Curve of influence of liquid to liquid ratio

It can be seen from Fig. 2 that the extraction rate of flavonoids from grapefruit seed increased first and then decreased with the increase of the ratio of material to liquid. When the ratio of liquid to liquid increased from 1:30 to 1:40, the extraction rate increased from $2.361 \mathrm{mg} / \mathrm{mL}$ Increased to $2.815 \mathrm{mg} / \mathrm{mL}$; when the ratio of material to liquid $1: 50$, the extraction rate decreased to $2.497 \mathrm{mg} /$ $\mathrm{mL}$. Therefore, in other circumstances the same circumstances, the liquid ratio should be selected at $1: 40$ or so.

2. Effect of Ultrasonic Power on the Extraction of Flavonoids from Grapefruit Seed

The extraction temperature was $50{ }^{\circ} \mathrm{C}$, the ratio of solid to liquid was $1: 30(\mathrm{~g} / \mathrm{mL})$, and the extraction time was $20 \mathrm{~min}$. The effect of ultrasonic power (w) on the extraction of flavonoids from grapefruit seeds was studied. The results are shown in Fig.3. 


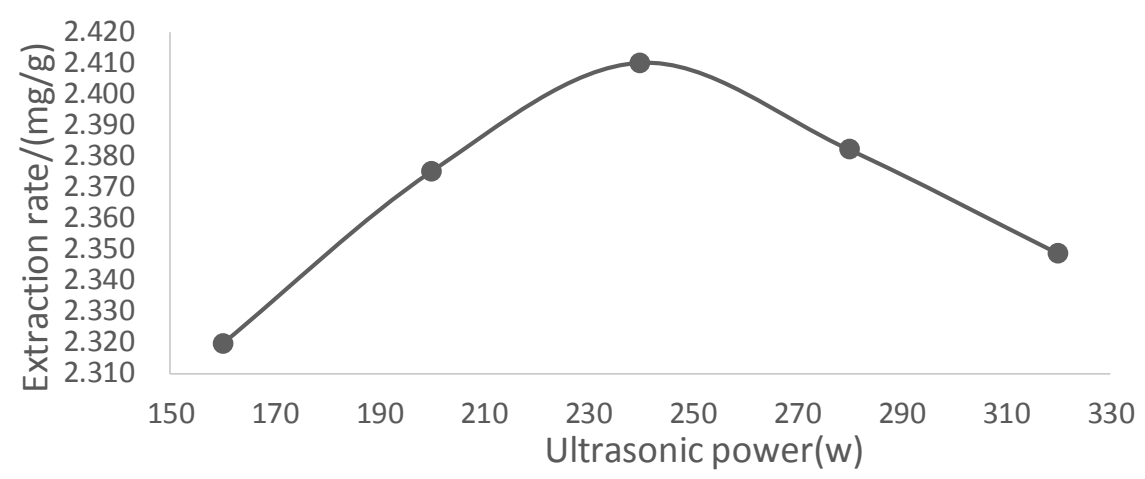

Figure 3. Effect of ultrasonic power curve

It can be seen from Fig. 3 that the extraction rate of flavonoids from grapefruit seed increased with the increase of extraction power, and increased from $2.375 \mathrm{mg} / \mathrm{mL}$ to $2.410 \mathrm{mg} / \mathrm{mL}$ when the extraction power increased from $200 \mathrm{w}$ to $240 \mathrm{w}$; When the extraction power was $280 \mathrm{w}$, the extraction rate was reduced to $2.382 \mathrm{mg} / \mathrm{mL}$. Therefore, the other factors in the same conditions, the extraction power should be selected in $240 \mathrm{w}$ or so.

3. Effects of Extraction Temperature on the Extraction of Flavonoids from Grapefruit Seed

The extraction temperature was $240{ }^{\circ} \mathrm{C}$ and the extraction time was $20 \mathrm{~min}$. The effect of extraction temperature $\left({ }^{\circ} \mathrm{C}\right)$ on the extraction of flavonoids from grapefruit seed was studied. The results are shown in Fig.4.



Figure 4. The temperature of the extraction curve

It can be seen from Fig. 4 that the extraction rate of flavonoids from grapefruit seed increased first and then decreased with the increase of extraction temperature. With the extraction temperature rising from $60{ }^{\circ} \mathrm{C}$ to $65{ }^{\circ} \mathrm{C}$, the extraction rate of flavonoids $2.463 \mathrm{mg} / \mathrm{g}$ to $2.527 \mathrm{mg} / \mathrm{g}$. The reason is that with the increase of temperature, the speed of molecular motion is accelerated, the penetration, diffusion and dissolution rate are accelerated. At the same time, the high temperature can cause the change of cell membrane structure, and the flavonoids are transferred from the outer cells of grapefruit seed to the solvent. Therefore, with the increase of extraction temperature, the extraction rate of flavonoids increased. With the further increase of temperature, the extraction rate of flavonoids decreased, which may be due to the increase of ethanol evaporation, the actual concentration of ethanol in the leaching solution decreased, the polarity increased slightly, the impurity increased, the insoluble matter adsorbed The flavonoids, resulting in the loss of flavonoids in the leachate, may also be caused by high temperature damage to certain flavonoids [2]. Therefore, the other factors in the same conditions, the extraction temperature should be selected at about $65{ }^{\circ} \mathrm{C}$. 
4. Effects of Extraction Time on the Extraction of Flavonoids from Grapefruit Seed

The extraction temperature was $50{ }^{\circ} \mathrm{C}$ and the extraction time (min) was used to extract the flavonoids from the grapefruit seed. The results are shown in Fig.5.



Figure 5. Extraction time of the impact of the curve

It can be seen from Fig. 5 that the extraction rate of flavonoids from grapefruit seed increased first and then decreased with the increase of extraction time. When the extraction time increased from $20 \mathrm{~min}$ to $25 \mathrm{~min}$, the extraction rate increased from $2.343 \mathrm{mg} / \mathrm{mL}$ to $2.410 \mathrm{mg} / \mathrm{mL}$ And the extraction rate was reduced to $2.266 \mathrm{mg} / \mathrm{mL}$ when the extraction time was $30 \mathrm{~min}$. Therefore, the other factors in the same conditions, the extraction time should be selected in $25 \mathrm{~min}$ or so.

\section{Conclusion}

The results showed that the factors affecting the extraction of flavonoids from grapefruit were in the order of ratio of material to liquid, ultrasonic power, extraction time and extraction temperature. The extraction rate of flavonoids from grapefruit seed increased with the increase of the ratio of liquid to material. The extraction rate of flavonoids from grapefruit seed increased first and then decreased with the increase of ultrasonic power. With the increase of extraction temperature, The extraction rate of flavonoids from grapefruit seeds increased first and then decreased with the increase of extraction time.

\section{Acknowledgements}

This work is supported by Guangdong Province Student Innovation Experiment Project (No. 201710573029)

\section{References}

[1] Ringseis R,Wen G, Saal D, et al. Conjugated Linoleic Acid Isomers Reduce Cholesterol Accumulation in Acetylated LDL-Induced Mouse RAW264.7 Macrophage-Derived Foam Cells.[J]. 2008,43(10):913-923.

[2] Forsythe C E, French M A, Goh Y K, et al. Cholesterolaemic influence of palmitic acid in the sn-1,3 v. the sn-2 position with high or low dietary linoleic acid in healthy young men.[J]. 2007,98(2): 337-344.

[3] Miura K, Stamler J, Nakagawa H, et al. Relationship of dietary linoleic acid to blood pressure: the International Study of Macro-Micronutrients and Blood Pressure Study.[J]. 2008, 52(2): $408-414$.

[4] Vermunt S H, Mensink R P, Simonis M M,et al. Effects of dietary alpha-linolenic acid on the conversion and oxidation of 13C-alpha-linolenic acid.fJ]. 2000,35(2): 137-142. 
[5] Osada K, Kodama T, Yamada K, et al. Dietary oxidized cholesterol modulates cholesterol metabolism and linoleic acid desaturation in rats fed high-cholesterol diets.[J]. 1998, 33(8): 757-764. 